\title{
Robots with artificial intelligence and spectroscopic sight in Hi-Tech labor market
}

\author{
Evgeniy Bryndin* \\ Research Center "ESTESTVOINFORMATIKA", Novosibirsk, Russia
}

\begin{abstract}
The artificial intelligence of the robot is the digital double of intelligence of the person capable to training, retraining, self-realization and development of professional and behavioural creative innovative competences and skills. The robot represents a technological and program cognitive complex. The realization of artificial intelligence the robot is enabled on the basis of criterion of preferences of improvement of functional activity by realization of actions of function of usefulness and high-quality selection of extensive statistics of the accumulated professional and behavioural creative innovative competences and skills of the person. The spectroscopic sight of the robot perceives objects and objects of their range of frequencies. For training of the robot in recognition of objects and objects the frequency spectral technology of machine learning is used. The spectroscopic sight perceives a range of radiations of objects, and the artificial trained neural network distinguishes them on a range.
\end{abstract}

\section{Introduction}

Robots can solve a set of various practical problems. The medicine, bank service, the industry, education, hotel business and even entertainments are the main scopes of robots.

Health care-one of the most progressive spheres in which work of robots is applied. Now actively the robotic surgery develops. In medicine will reach big break since bionic artificial limbs which the person can operate by means of own nervous system began to be used. Moreover, by means of an artificial limb of people can feel touch, heat and pressure.

Robotic systems apply in the sphere of safety: devices with special sensors quickly find fire-dangerous situations and successfully prevent them.

The modern plants and the enterprises far promoted due to modern technologies. The automated industrial robots are used to welding, laying, painting and other operations demanding repeated repetition and high precision.

Recently the smart home-the automated network controlling electricity, water supply, safety and other systems enjoys the increasing popularity.

In Japan, Russia, Taiwan, China and other developed countries were created androids who are able to support a conversation and even to joke.

Robots become independent subjects of social environment. Social cognitive smart robots are used as guide, seller, lecturer, vacuum cleaner, nurse, volunteer, security guard, administrator of hotel. Consultant, lecturer and teacher (Figure 1). Robot-Android volunteer ASIMO (Figure 2). Mobile robot security guard Atlas (Figure 3). Japanese robot-administrator of hotel Henn-na Hotel (Figure 4).

Astronauts robots are actively used by the person in development of open spaces of the Universe. They collect samples of the soil and investigate new spaces in the conditions of the raised radiation and extreme temperatures. The Russian FEDOR Robot (Final Experimental Demonstration Object Research)-anthropomorphous robot is astronaut Skybot F-850 (Figure5).

There are robots for hi-tech work which on teeth to artificial intelligence.

With the advent of artificial neural networks in the modern world robots learned to create. In modern life of people already uses robots in all spheres of the activity. In the majority robots are not replaceable assistants. The person tries to create, for the robots, artificial intelligence.

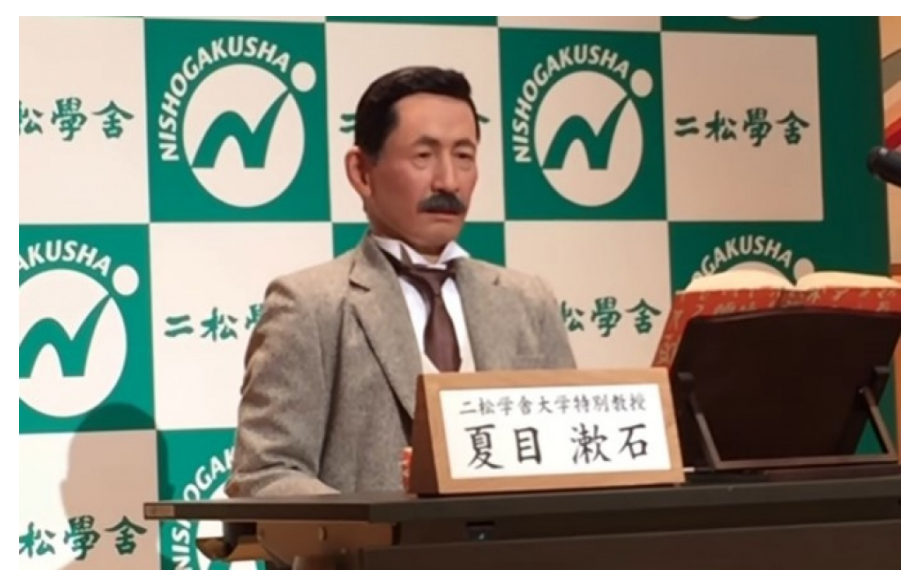

Figure 1. Japanese robot lecturer

${ }^{*}$ Correspondence to: Evgeniy Bryndin, Research Center "ESTESTVOINFORMATIKA", Russia, Novosibirsk, E-mail: bryndin15@yandex.ru

Key words: artificial intelligence of the robot, digital double, criterion of preferences, function of usefulness, qualitative selection, spectroscopic sight, frequency spectral technology of machine learning

Received: August 19, 2019; Accepted: September 02, 2019; Published: September 09, 2019 
With artificial intelligence robots will be able independently to estimate the events around them and to make decisions on actions which they need to make.

In article approach to creation of robots with spectroscopic sight and artificial intelligence, capable to work at the market of hi-tech work briefly is considered.

\section{Cognitive clever architecture of the robot}

The cognitive clever architecture includes artificial neural networks, algorithms of machine learning, the cognitive smart big data system, the system of high-quality selection. The cognitive

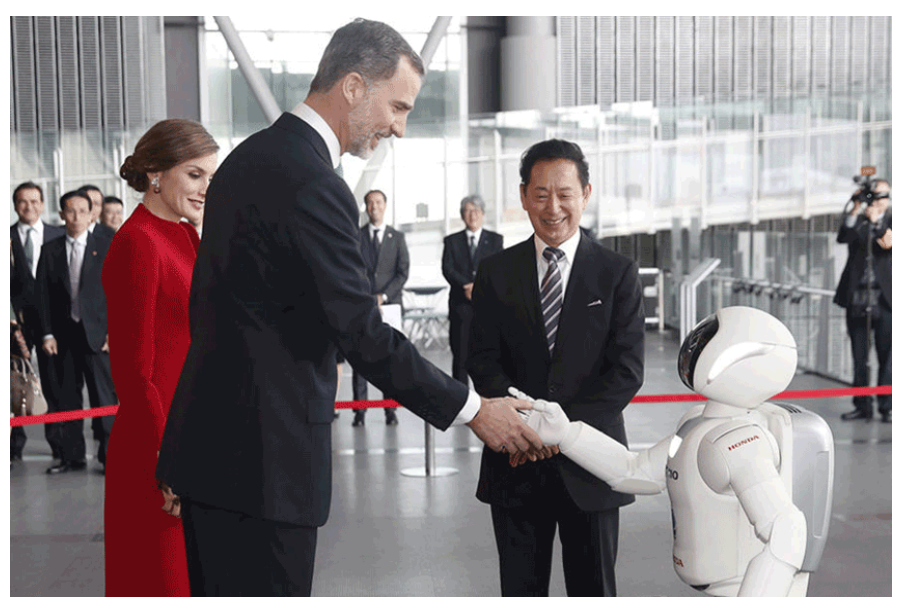

Figure 2. Japanese robot-Android volunteer ASIMO

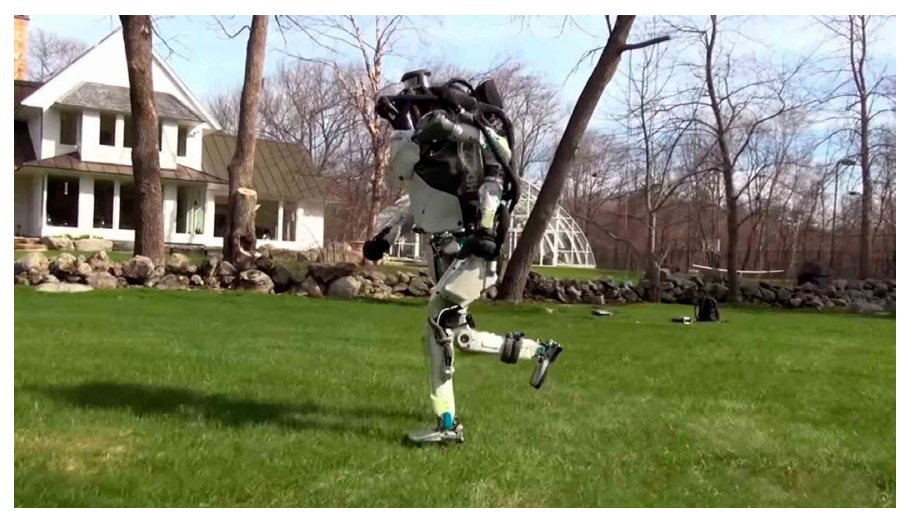

Figure 3. American mobile robot security guard Atlas

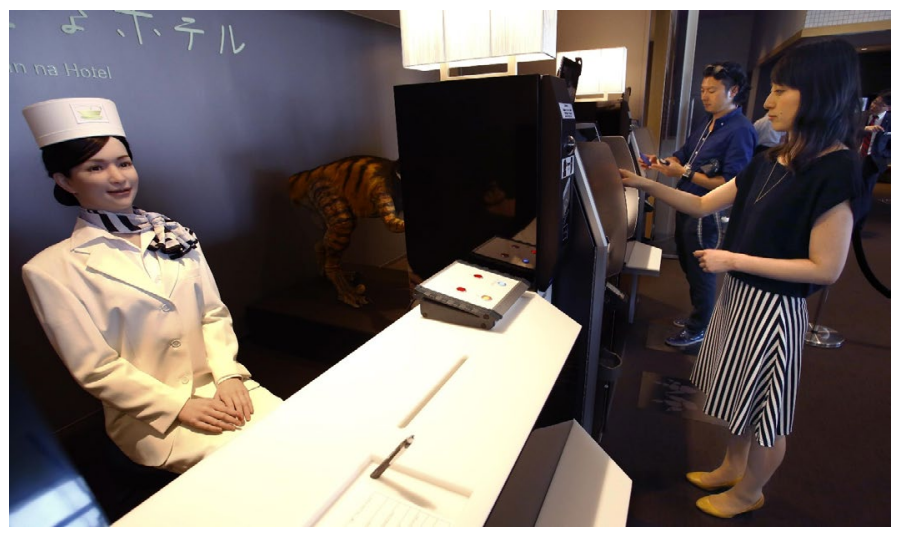

Figure 4. Japanese robot-administrator of hotel Henn-na Hotel

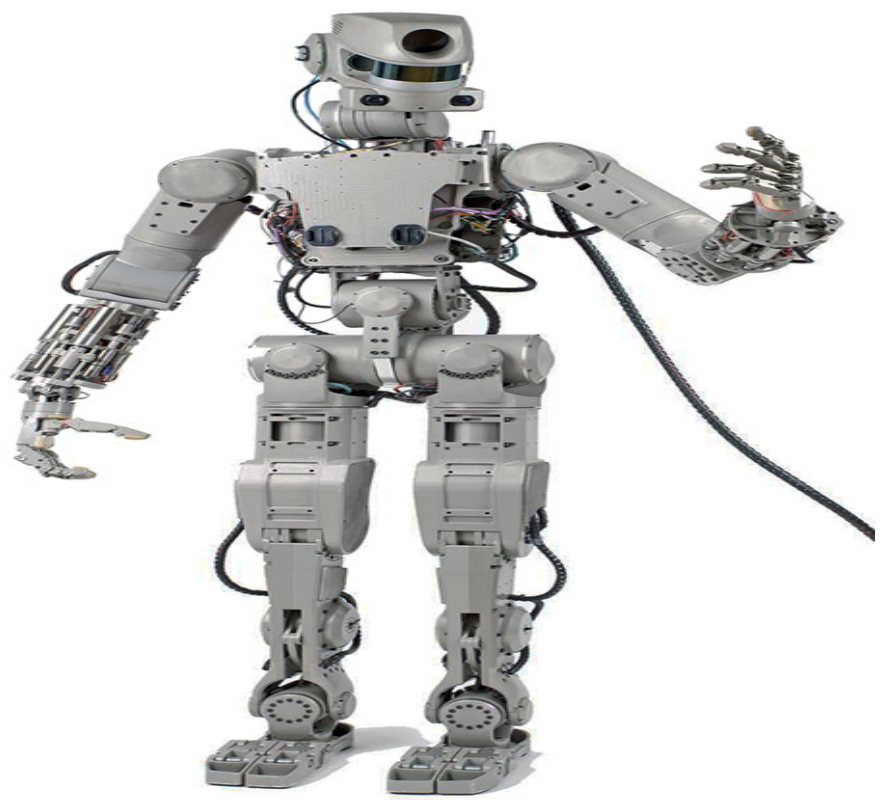

Figure 5. FEDOR robot

architecture of the robot on the basis of criterion of preferences develops functional activity. The clever cognitive architecture of the robot step by step defines how it is the best of all to achieve the set objectives and to realize preferences by means of actions of function of usefulness on the basis of high-quality selection. Professional self-improvement is carried out by machine retraining by criterion of preferences on the basis of extensive statistics of high-quality selection of the saved-up creative innovative skills and competences in the sixth technological way of the industry 4.0. The clever cognitive architecture of the robot develops its artificial intelligence by machine retraining, on the basis of extensive statistics of the creative innovative competences and of base of abilities of the corresponding professional and behavioural skills accumulated in the knowledge base [1-11].

\section{Approaches to detection of preferences}

To reveal preference on a set of objects A, it means to specify a set of all those couples of objects (and, b), for which an object and it is more preferable, than $b$. At detection of preference the following approaches are possible.

\section{Unconditional approach on the basis of the table}

Let's fill out the table by the principle:

$a i j=1$ if $i-y$ an object is better than object $j$;

$a i j=0$ if $i-y$ an object is worse than object $j$.

\section{Logical approach}

Approach includes three stages:

- private criteria by which there is a choice of preferences are distinguished;

- the table "alternative-part criteria" in which for each alternative values of quantitative private criteria or ranks of qualitative criteria are specified is formed.

- the decisive rule for definition of the best alternative is chosen. 
As the considered private criteria - qualitative, are given them not quantitative, but rank estimates (on preferences). Rank estimates can be considered as points. On their basis it is necessary to define preference. The decisive rule is for this purpose created. For example, 1,2,3.

1. Absolute preference: The alternative of ai is more preferable than aj alternative if by all private criteria of ai aj is more preferable or is equivalent to it. The absolute preference has property of transitivity (if And more preferably it is more preferable than B and B With, then $\mathrm{A}$ is more preferable than $\mathrm{C}$ ).

2. Preference by the rule of the majority: The alternative of ai is better, than aj if the amount of private criteria by which ai is better than aj are more than amount of criteria by which ai is worse than aj.

3. Criterion of the largest sum of mark estimates: Instead of quantitative estimates of private criteria it is possible to put down their rank values. The value of a rank is considered as mark assessment, and for the worst value the smallest point-1, and for the best value-the greatest point is given. Then the criterion of preference is formulated so: the alternative of ai is better than aj alternative if the sum of mark estimates for ai is more, than for aj.

When using criteria of preference by the rule of the majority or the sum of mark estimates often the additional requirement - lack of private criterion with the worst value is imposed on an alternative. Such alternatives are excluded from consideration at once.

At a large number of alternatives and private criteria direct definition of the best alternative by criterion of the majority becomes difficult because of complexity of calculation of number of the best and worst criteria for each alternative. In this case for allocation of the best alternative it is necessary to make the table of preferences.

By the rule of the majority and lack of the worst value the table of preferences for alternatives is formed: if the alternative of $b$ is more preferable than $a$, then on crossing of line $b$ and column a is put 1 , differently 0 .

\section{Useful choice}

Useful choice is function by means of which it is possible to present preferences on some set of unrealized hi-tech demand. The concept "usefulness" was entered into economic science by the English philosopher Jeremiah Bentam (1748-1832). Today all science about market economy, in fact, keeps on two theories: usefulness and cost. By means of category of usefulness operation of the law of demand speaks. The digital double of artificial intelligence of the robot analyzes unrealized demand for hi-tech products in the market. The choice of unrealized demand for hi-tech products in the market in practice is connected with use of key indicators of cost efficiency of NPV, IRR, PB, $\mathrm{PL}, \mathrm{ROI}$ and other. The robot determines the participation in unrealized demand for hi-tech products by key indicators of cost efficiency. He chooses and masters new competences and skills of technological program functional selling of goods or services for operational satisfaction of demand with the smallest costs of production [12-16].

\section{Spectroscopic sight of the robot}

Studying of feature of interaction of the radiation (light) with particles which size less than the wavelength is engaged nanooptics. Technologies in the field of nanooptics include the scanning optical microscopy of the near field, the photostrengthened scanning tunnel mikroskopiiya and spectroscopy of a superficial plazmonny resonance. The traditional microscopy for exact focusing of light uses diffraction elements for the purpose of increase in permission. However, because of a diffraction limit (known as criterion of permission of Rayleigh) the spreading light can be focused in a spot with the minimum diameter which is a half of wavelength of light. Therefore, for diffraction and limited microscopy the most achievable permission is about two hundred nanometers.

In 2014. The Nobel Prize in chemistry was awarded to Eric Bettsigu (USA), William Merner (USA) and Stefan Hell (Germany) for development of methods of fluorescent microscopy with the ultrahigh permission. These methods were widely adopted since 2008 when the microscopy of ultrahigh permission was recognized as "method of year" in special issue of the Nature Methods magazine. The key moment of a method - is obtaining information on various parts of a nanoobject independently of each other. Scanning two lasers with the bright center, you pass on all sample and see very thin structure with the permission in nanometers. This system is called a nanoskopiya. Nanoskopiya allows to see very thin structures. Specification of the obtained information increases. Now the optical nanoskopiya with over permission can use for realization of frequency spectral sight of robots.

The spectroscopic sight of the robot helps it to perceive frequency ranges of objects and objects of the environment. The artificial trained neural network distinguishes their range, is associative compares to the saved-up ranges of objects and objects in the frequency base. By associative comparison defines a subject or an object [17].

\section{Conclusion}

Technologies of artificial intelligence hold special position in structure of digital transformation, affecting all spheres of our life: from a consumer sector before the industry. Technologies of artificial intelligence are widely demanded in the most different branches of digital economy, but their full-scale practical use constrains backwardness of the regulatory base so far. To simplify understanding, to facilitate introduction, to remove regulatory barriers concerning technologies of artificial intelligence to the widest audience of potential users standardization in the field of technologies of artificial intelligence within the International Organization for Standardization (ISO) is carried out, first of all. Participants and leaders of discussion are representatives of the companies-developers of the technologies and solutions of artificial intelligence interested in creation of the favorable environment in economy and in society for effective implementation of artificial intelligence in practice. Algorithms, methods and technologies of artificial intelligence constantly extend in the direction of natural intelligence.

Artificial Intelligence becomes scientific applied direction on development and creation of technological and program cognitive complexes of the digital double of intelligence of the person of technological and program cognitive complexes of the digital double of intelligence of the person capable to training, retraining, self-realization and self-improvement on the basis of criterion of preferences and to improvement of functional activity by the high-quality choice and development of creative innovative hi-tech professional and behavioural skills and competences.

\section{References}

1. Bryndin EG (2015) The Robot with imitative thinking. "PNIPU bulletin: Electrical equipment, Information technologies, Control systems", PNIPU 14: 5-36.

2. Vernon D (2014) Artificial Cognitive Systems. MIT Press, Cambridge, Massachusetts London, England 70

3. Samani H (2015) Cognitive Robotics. CRC Press 220. 
4. Bryndin EG (2016) Cognitive robot consultant for a healthy lifestyle. III International scientific conference "Information Technologies in Science, Management, the Social Sphere and Medicine". TPU 484-488.

5. Bryndin EG (2016) Cognitive robots. Inter. Conf. "Management of development of large-scale systems. IPM RAS 285-294.

6. Bryndin E (2017) Cognitive Robots with Imitative Thinking for Digital Libraries, Banks, Universities and Smart Factories. Intern J Management and Fuzzy Sys 3: 57- 66.

7. Bryndin E (2008) Technological Thinking, Communication and Behavior of Androids. Communications 6: 13-19.

8. Wermter S, Palm G and Elshaw M (2005) Biomimetic Neural Learning for Intelligent Robots: Intelligent Systems, Cognitive Robotics, and Neuroscience. Springer-Verlag Berlin Heidelberg 389.

9. Al-Araji AS and Dagher KE (2015) Cognitive Neural Controller for Mobile Robot. IJCCCE 15: 46-60.

10. Bryndin E (2017) Program Hierarchical Realization of Adaptation Behavior of the Cognitive Mobile Robot with Imitative Thinking. Intern J Eng Management 1: 74-79.
11. Bryndin E (2019) Social Cognitive Smart Robots: Guide, Seller, Lecturer, Vacuum Cleaner, Nurse, Volunteer, Security Guard, Administrator. Communications 7: 6-12.

12. Bryndin E (2018) Technological, Economic and Social Aspects of Management by Development of the Digital Industry 4.0. Intern J Managerial Stud \& Res (IJMSR) 6: 19-30.

13. Bryndin E (2018) Directions of Development of Industry 4.0, Digital Technology and Social Economy. American J Info Sci and Technol 2: 9-17.

14. Bryndin E (2019) Human Digital Doubles with Technological Cognitive Thinking and Adaptive Behaviour. Software Engineering 7:1-9.

15. Bryndin E (2019) System retraining to professional competences of cognitive robots on basis of communicative associative logic of technological thinking. Intern Robotics Automation J 5: 112-119.

16. Bryndin E (2019) Creative innovative transformational ecosystem of formation of humane technological society. Intern Robotics Automation J 5: 91-94.

17. Bryndin EG, Putmakov AN (2019) Frequency color visualization of a condition of the person according to spectral analysis of biofield and biodiagnostics. J Med Prac \& Rev 3: 505-509.

Copyright: (C2019 Bryndin E. This is an open-access article distributed under the terms of the Creative Commons Attribution License, which permits unrestricted use, distribution, and reproduction in any medium, provided the original author and source are credited. 